\title{
Home visits in general practice - most often for elderly patients: A report from the Møre \& Romsdal Prescription Study
}

\author{
Jørund Straand, MD and Hogne Sandvik, MD, PhD \\ Division for General Practice, Department of Public Health and Primary Health Care, University of Bergen, \\ Ulriksdal 8c, N-5009 Bergen, Norway \\ Telephone +4755586100 Telefax +4755586130 E-mail Jorund.Straand@isf.uib.no
}

\begin{abstract}
Objectives: Although home health care has been the fastest growing segment of the health care system during the last decades, general practitioners' (GPs') home visiting rates have declined. The aim of this study was to analyse home visits in relation to characteristics of both patients and GPs, the diagnoses, and the drugs prescribed.

Methods: A cross-sectional descriptive study in the Norwegian county of Møre \& Romsdal. All encounters $(90,458)$ and prescriptions $(74,079)$ issued during two months were recorded.

Results: 5.074 home visits were recorded (9.2\% of all face-to-face contacts). Home visiting rates were highest for the elderly and for children. Most home visits were for new diagnoses, and 28\% took place during weekends. Infections in the respiratory tract comprised the majority of the diagnoses for visiting children, whereas coronary heart disease and heart failure were the most frequent diagnoses for visiting the elderly. Drugs were prescribed during $48.9 \%$ of the home visits. General systemic antiinfectives and respiratory drugs comprised $53 \%$ of all prescriptions, whereas CNS-drugs comprised another $20 \%$. Doctors' characteristics associated with doing home visits were male gender, young age, GP specialisation, fixed salary, and rural location.

Conclusions: Home visiting policy should be more selective. While most children could be adequately taken care of by telephone consultations or consultations in the surgery, home visits should be encouraged for the chronically ill and the housebound.
\end{abstract}

\section{INTRODUCTION}

Until the last decades, visiting patients in their homes used to be a major part of general practice. ${ }^{1}$ In $1952-55$ a Norwegian general practitioner (GP) reported that $18 \%$ of his contacts with patients took place in their homes. ${ }^{2}$ In the 1970 's, however, only $5-6 \%$ of the contacts were home visits. ${ }^{3,4}$ This proportion of home visits increased again after the 1970 's, reaching approximately $10 \%$ of all contacts with patients in the late 1980 's. ${ }^{5}$ A similar proportion was reported from United Kingdom in the early 1990 's. ${ }^{6}$ In other countries, the decline in home visiting rates has continued. It is now in fact almost twice as common for elderly Americans to undergo a cardiac catheterization than to have a physician coming to visit them at home. ${ }^{7}$ The decline in home visits is partly explained by the increasing use of technology in medicine and that many GPs therefore view home visits as both outdated and impractical. ${ }^{8,9}$

On the other hand, home care is now the fastest growing sector of medicine, and in the US this sector has increased at approximately $20 \%$ per year during the last decade. ${ }^{10}$ This development is also facilitated by new technology that makes it possible to do even more of traditional hospital activities in the patients' own homes. "New" professions like home nurses and social workers have taken over much of the responsibility for this home based care. ${ }^{8,10}$

It is generally agreed that a home visit strengthens the GP-patient relationship, and that it may provide valuable information and insights that is useful for the GP. ${ }^{8}$ However, while scheduled home visits for the chronically ill and the housebound should be encouraged, most home visits nowadays are probably performed for acute illnesses, out of hours, during nights, and often to other GPs' patients..$^{11-13}$ Many GPs are dissatisfied by the high workload and the low payment during out of hours periods, and this has prompted reforms to reduce the number of home visits in general practice. ${ }^{14}$

To plan for a more rational use of home visits, it is important to have detailed knowledge about the patients and GPs typically involved. The aims of the 
present study were to determine the characteristics of the GPs who make home visits, their patients, demographic variables, diagnoses, and the drugs prescribed.

\section{METHODS}

This article is a report from the Møre \& Romsdal Prescription Study (MRPS) in which almost all GPs in the Norwegian county of Møre \& Romsdal recorded all contacts with patients and prescriptions during November 1988 and November 1989. Details about the MRPS have been described elsewhere. ${ }^{15}$

During the survey the GPs used a specially designed prescription form, a carbon copy of which was retained with a questionnaire. On this the GPs completed data about the kind of contact (direct or indirect; first time or follow-up), the diagnosis, and if the patient was referred. In case of drug prescriptions the GPs also filled in diagnostic indication(s) for each prescription, and whether the prescription was initial or repeat. The 12 pharmacies in the county kept a record every time a GP used his or her private prescription form instead of the form made for this study. This showed that other forms were used in less than $0.5 \%$ of the cases. ${ }^{15}$

Drugs were classified according to the Anatomical Therapeutic Chemical (ATC) Classification System. ${ }^{16}$ Defined Daily Doses (DDD) and DDDs per prescription (DDD/P) were used to give the prescribed amounts. One DDD is defined as the assumed average daily dose for the main indication of the drug. ${ }^{16}$

Population-based home visiting rates were calculated as the number of home visits per 1000 inhabitants per year, excluding those living in nursing homes or other long-term care facilities, and based on the assumption that the number of visits per year was sixfold the numbers recorded during the two months' survey. The home visiting rate for each GP was calculated as the proportion of all face-to-face contacts.

A forward conditional multiple logistic regression analysis was performed in order to examine possible explanatory variables for doing house calls $v s$. other types of contacts. The following explanatory variables were examined: patients' sex, patients' age group (0-9, $10-19,70-79, \geq 80$; each $v s$. the rest of the total), first contact $v s$. control, doctors' sex, doctors' age $(\leq 38$ years $v s .>38$ years; the median age), doctors' experience ( $<10$ years $v s . \geq 10$ years), GP specialisation, fixed salary $v s$. fee for service, solo $v s$. group practice, rural $v s$. urban location, weekend $v s$. rest of week, and year (1988 vs. 1989).

Statistical significance was accepted at $\mathrm{p}<0.05$, and the confidence intervals given are $95 \%$.

\section{MATERIAL}

Of the 156 GPs in the county, 149 (95.5\%) participated in the MRPS during the first period. The participation rate rose to $98 \%$ during the second period.
Altogether, there were 90,458 GP-patient contacts, 74,079 drug prescriptions, and 55,198 face-to-face contacts of which 5,074 (9.2\%) were home visits. For 245 home visits there were incomplete data regarding patients' age or sex. During the remaining 4,829 home visits, 3,125 prescriptions were issued.

On January 1st 1989, the population of the county was 238,287 of which 1514 were living in nursing homes or other long term care facilities.

\section{RESULTS}

The number of home visits corresponds to 130 visits per 1000 inhabitants per year. The home visiting rates were highest for children (0-4 year olds; 264 visits/ 1000 inhabitans/year) and for the elderly (80 years and over, 362 visits/1000 inhabitants/year) (Figure 1). The mean home visiting rate for each GP was $9.8 \%(95 \%$ confidence interval $8.3 \%$ to $11.2 \%$ ). Twenty-five GPs did not record any home visits, 11 GPs recorded home visiting rates over $25 \%$. More than one fourth $(27.7 \%)$ of the visits were performed during weekends.

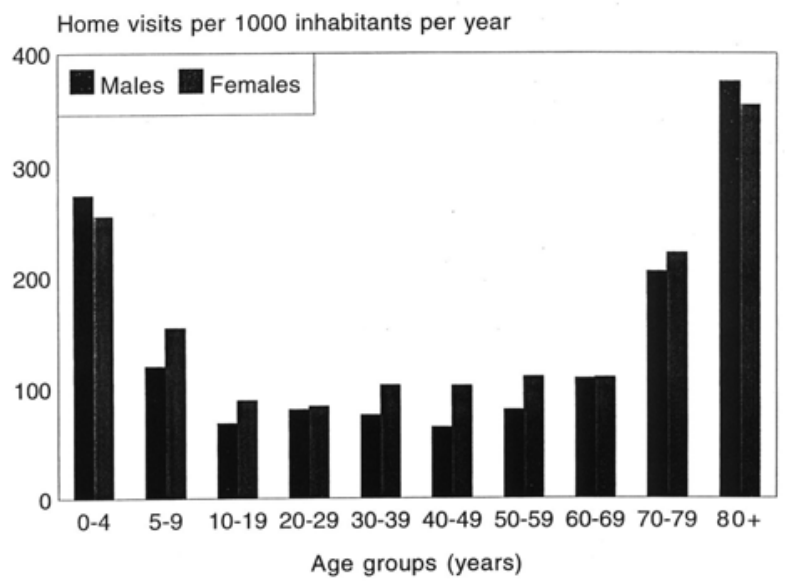

Figure 1. Estimated population based home visiting rates (numbers of home visits per 1000 inhabitants per year) in general practice by patients' sex and age group.

Patients were most frequently visited for infections in the respiratory tract $(25.1 \%$ of all $)$, and the twenty most commonly recorded diagnoses comprised $56.2 \%$ of all (Table 1). While upper respiratory tract infections (URTI), skin injuries and low back pain were relatively more frequent reasons for visiting male patients, females were seen more often for cystitis, depression, and anxiety. Infections in the respiratory tract comprised the majority of the diagnoses for visiting children younger than ten years old. Among the elderly (60-79), coronary heart disease (CHD) was the most commonly recorded diagnosis, while for the oldest $(80+)$ heart failure (HF) was the number one diagnosis.

Most $(71.5 \%)$ of the patients visited in their homes were seen for problems that were new to this doctor. 
Table 1. The twenty most common diagnoses for making home visits in general practice by: patients' sex, patients' age group, the proportion of the visits that were for new problems, and the proportion who received drug prescription $\left(\mathrm{R}_{\mathrm{x}}\right)$ during the visit.

\begin{tabular}{|c|c|c|c|c|c|c|c|c|c|c|c|c|c|c|c|c|}
\hline \multirow[b]{2}{*}{ No. Diagnoses } & \multicolumn{3}{|c|}{ Patients' sex } & \multicolumn{9}{|c|}{ Patients' age groups (years) $(\%)$} & \multicolumn{2}{|c|}{$\mathrm{Su} \mathrm{m}$} & \multirow{2}{*}{$\begin{array}{l}\text { New diag- } \\
\text { nosis (\%) }\end{array}$} & \multirow[b]{2}{*}{$\mathrm{R}_{\mathrm{x}}(\%)$} \\
\hline & M & $\mathrm{F}$ & $\Delta$ & $0-9$ & $10-19$ & $20-29$ & $30-39$ & $40-49$ & $50-59$ & $60-69$ & $70-79$ & $80+$ & $\%$ & $\mathrm{n}=$ & & \\
\hline 1. UpperRespTractInfect & 7.0 & 5.2 & $!$ & 15.9 & 6.7 & 4.5 & 5.0 & 2.8 & 2.4 & 2.1 & 1.1 & 1.6 & 6.0 & 290 & 88 & $\overline{61}$ \\
\hline 2. Otitis & 4.7 & 4.2 & - & 13.5 & 0.9 & 2.3 & 1.6 & 1.8 & 1.5 & 0.7 & 0.0 & 0.6 & 4.4 & 214 & 88 & 83 \\
\hline 3. Acute bronchitis & 3.8 & 3.8 & - & 6.2 & 4.7 & 2.3 & 3.6 & 2.8 & 3.4 & 3.0 & 1.7 & 3.5 & 3.8 & 182 & 73 & 88 \\
\hline 4. AbdomPain/UlcerDisease & 3.2 & 3.9 & - & 2.6 & 3.6 & 3.8 & 3.2 & 5.1 & 2.7 & 3.9 & 3.8 & 4.3 & 3.6 & 172 & 68 & 25 \\
\hline 5. Tonsillitis & 3.8 & 3.0 & - & 7.9 & 7.7 & 3.8 & 2.8 & 0.8 & 0.3 & 0.0 & 0.8 & 0.0 & 3.4 & 162 & 87 & 91 \\
\hline 6. Pneumonia & 2.9 & 3.6 & - & 2.7 & 4.0 & 0.6 & 2.0 & 2.0 & 2.1 & 3.5 & 4.4 & 7.4 & 3.3 & 158 & 80 & 78 \\
\hline 7. Fractures/Distortions & 3.2 & 3.3 & - & 1.8 & 5.5 & 4.5 & 2.4 & 2.8 & 3.7 & 2.8 & 4.7 & 2.3 & 3.2 & 156 & 93 & 20 \\
\hline 8. Acute cystitis & 1.7 & 3.5 & $!$ & 1.8 & 2.6 & 3.8 & 2.8 & 2.0 & 2.4 & 3.2 & 2.7 & 3.9 & 2.7 & 131 & 71 & 83 \\
\hline 9. Low back pain & 3.5 & 2.0 & $!$ & 0.3 & 1.0 & 5.5 & 5.0 & 4.6 & 7.0 & 3.0 & 2.5 & 0.4 & 2.7 & 131 & 72 & 63 \\
\hline 10. Coronary heart disease & 2.7 & 2.6 & - & 0.2 & 0.2 & 0.6 & 0.8 & 1.8 & 6.4 & 5.6 & 6.0 & 5.8 & 2.7 & 130 & 63 & 32 \\
\hline 11. Skin injuries/ulcers & 3.4 & 1.5 & $!$ & 2.6 & 3.8 & 4.2 & 4.0 & 2.5 & 0.9 & 1.9 & 0.8 & 0.4 & 2.4 & 114 & 94 & 14 \\
\hline 12. Fever & 2.6 & 2.0 & - & 7.3 & 3.0 & 0.8 & 0.2 & 0.3 & 0.0 & 0.7 & 0.5 & 1.4 & 2.3 & 111 & 81 & 22 \\
\hline 13. Heart failure & 2.7 & 1.9 & - & 0.8 & 0.8 & 0.2 & 0.2 & 0.0 & 1.8 & 3.9 & 4.9 & 8.2 & 2.3 & 110 & 54 & 34 \\
\hline 14. MusclesJointsTendons*) & 1.7 & 2.6 & $!$ & 0.2 & 1.6 & 2.8 & 2.6 & 4.6 & 4.9 & 3.0 & 2.7 & 1.4 & 2.2 & 107 & 74 & 67 \\
\hline 15. Asthma & 2.3 & 2.2 & - & 3.8 & 2.0 & 0.0 & 1.0 & 2.0 & 0.6 & 4.6 & 2.2 & 1.6 & 2.2 & 107 & 55 & 66 \\
\hline 16. Depression & 1.6 & 2.7 & $!$ & 0.0 & 0.2 & 1.9 & 3.4 & 5.1 & 4.3 & 3.5 & 3.0 & 2.1 & 2.2 & 106 & 27 & 30 \\
\hline 17. Skin infection & 2.2 & 2.0 & - & 1.3 & 2.2 & 2.5 & 2.2 & 2.0 & 3.4 & 2.3 & 1.9 & 2.1 & 2.1 & 100 & 70 & 67 \\
\hline 18. Anxiety/neurosis & 1.3 & 2.3 & $!$ & 0.1 & 1.0 & 1.5 & 3.4 & 3.8 & 4.0 & 2.3 & 2.7 & 0.8 & 1.8 & 89 & 34 & 41 \\
\hline 19. Influenza & 1.9 & 1.3 & - & 2.1 & 1.4 & 2.1 & 2.4 & 1.5 & 1.2 & 1.4 & 0.5 & 1.0 & 1.6 & 75 & 93 & 21 \\
\hline 20. Sinusitis & 1.3 & 1.6 & - & 0.4 & 2.0 & 3.4 & 3.4 & 2.5 & 2.1 & 0.7 & 0.3 & 0.0 & 1.4 & 69 & 82 & 91 \\
\hline Sum diagnoses (1-20) & 57.4 & 55.2 & & 71.4 & 61.1 & 51.4 & 51.6 & 50.9 & 55.2 & 52.2 & 46.9 & 48.6 & 56.2 & 2714 & & \\
\hline Other diagnoses & 42.6 & 44.8 & & 28.6 & 38.9 & 48.6 & 48.4 & 49.1 & 44.8 & 47.8 & 53.1 & 51.4 & 43.8 & 2115 & & \\
\hline Total & 100.01 & 100.0 & & 100.0 & 100.0 & 100.0 & 100.0 & 00.0 & 100.0 & 100.0 & 100.01 & 100.0 & 100.0 & 4829 & & \\
\hline $\mathrm{N}=$ & 2184 & 2645 & & 1057 & 494 & 471 & 504 & 393 & 328 & 431 & 637 & 514 & 4829 & 4829 & & \\
\hline
\end{tabular}

* Muscles, joints, and tendons: unspecified symptoms and complaints

$\Delta$ The $95 \%$ confidence interval for the difference between the proportions does not include zero (!), or does include zero (-)

However, this proportion varied with the diagnoses recorded, and only $27 \%$ of the depression cases were new (Table 1).

$10.2 \%$ of the patients visited were submitted to the emergency department in hospital. Among the top twenty diagnoses, the hospitalization rates were highest for fractures and distortions (47.3\%), HF (21.1\%), and CHD (19.4\%).

The GPs issued drug prescriptions during $48.9 \%$ of the home visits, but the prescribing rate varied significantly with the diagnoses (Table 1). Altogether drugs in the ATC classes general systemic antiinfectives and respiratory drugs comprised $53 \%$ of all prescriptions, whereas CNS-drugs comprised another $20 \%$ (Table 2). The ten most commonly prescribed therapeutic groups comprised more than $80 \%$ of all prescriptions (Table 3).

A total of 72,510 patient contacts were included in the multiple regression analysis (Table 4). Of these, 4,266 were home visits. Old and young patients were more prone to get house calls, as were male patients. Contacts during weekends, and first time contact for the problem were strong predictors for house calls. Doctors' characteristics associated with house calls were male gender, young age, GP specialisation, fixed salary, and rural location. The rest of the explanatory variables did not contribute significantly to the explained variance of the dependent variable.

\section{DISCUSSION}

\section{Methods}

This report is based on data from the so far largest survey on patient contacts in Norwegian general practice. ${ }^{15}$ The main strength of this study is that almost all the GPs in the county participated according to the protocol.

A limitation in our data is that the GPs did not record whether the visits were "acute" or "scheduled". Another limitation is that doctors may use some diagnoses to justify a treatment given, instead of vice versa (e.g. sleeping pills and insomnia). This may imply a possible over-representation of such diagnoses. However, we did not judge it as feasible to have standardized criteria for the diagnoses recorded by the GPs. This may represent a limitation of the validity, but the diagnoses used here probably are representative of diagnoses used by GPs during everyday practice. 
Table 2. General practitioners' drug prescriptions $(\mathrm{N}=3,125)$ issued during home visits distributed according to the ATC system main groups; by numbers of prescriptions, proportions of the prescriptions for male $(\mathrm{M})$ and female $(\mathrm{F})$ patients, and for different age groups, and the prescribed total volume, and the average amount issued per prescription (\#).

\begin{tabular}{|c|c|c|c|c|c|c|c|c|c|c|c|c|c|c|c|c|c|}
\hline \multirow[b]{3}{*}{ Drugs (ATC anatomical main classes) } & \multicolumn{14}{|c|}{ Prescriptions } & \multicolumn{3}{|c|}{ Volume prescribed } \\
\hline & \multicolumn{2}{|c|}{ Numbers } & \multicolumn{3}{|c|}{ Patients'sex } & \multicolumn{9}{|c|}{ Patients' age groups } & \multirow[b]{2}{*}{ DDDs } & \multirow[b]{2}{*}{$\%$} & \multirow[b]{2}{*}{$\mathrm{DDD} / \mathrm{P}$} \\
\hline & $\mathrm{n}=$ & $\%$ & M & $\mathrm{F}$ & $\Delta$ & $0-9$ & $10-19$ & $20-29$ & $30-39$ & $40-49$ & $50-59$ & $60-69$ & $70-79$ & $80+$ & & & \\
\hline Alimentary tract and metabolism & 157 & 5.0 & 4.3 & 5.6 & - & 1.5 & 1.5 & 2.6 & 4.9 & 3.7 & 5.9 & 9.2 & 10.0 & 9.5 & 4,316 & 8.2 & 27.5 \\
\hline Cardiovascular system & 161 & 5.2 & 5.7 & 4.7 & - & 1.0 & 1.8 & 0.3 & 1.4 & 1.5 & 6.8 & 10.4 & 13.9 & 12.5 & 14,669 & 27.8 & 101.2 \\
\hline General systemic antiinfectives & 1151 & 36.8 & 36.2 & 37.3 & - & 53.4 & 54.0 & 38.4 & 34.1 & 25.6 & 24.2 & 28.1 & 22.7 & 28.5 & 8,540 & 16.2 & 7.5 \\
\hline Musculoskeletal system & 190 & 6.1 & 6.3 & 5.9 & - & 0.9 & 3.4 & 9.6 & 8.7 & 8.9 & 10.5 & 7.2 & 6.5 & 7.1 & 2,888 & 5.5 & 15.3 \\
\hline Central nervous system & 625 & 20.0 & 18.5 & 21.2 & - & 8.4 & 6.1 & 16.9 & 24.6 & 33.0 & 26.5 & 26.9 & 29.9 & 23.1 & 10,712 & 20.3 & 17.3 \\
\hline Respiratory organs & 507 & 16.2 & 16.5 & 16.0 & - & 7.7 & 22.4 & 14.6 & 16.2 & 12.6 & 9.1 & 8.0 & 10.0 & 9.2 & 6,766 & 12.8 & 13.3 \\
\hline Sensory organs* & 151 & 4.8 & 7.1 & 3.1 & $!$ & 5.4 & 4.6 & 8.9 & 4.3 & 5.6 & 7.8 & 2.8 & 2.1 & 3.1 & 50 & 0.1 & 25.0 \\
\hline Others* $\quad * *$ & 183 & 5.9 & 5.4 & 6.2 & - & 1.7 & 6.1 & 8.6 & 5.8 & 9.3 & 9.1 & 7.2 & 4.9 & 7.1 & 4,749 & 9.0 & 43.2 \\
\hline SUM & 3,125 & 100.0 & 100.0 & 100.0 & & 100.0 & 100.0 & 100.0 & 100.0 & 100.0 & 100.0 & 100.0 & 100.0 & 100.0 & 52,690 & 100.0 & 18.3 \\
\hline $\mathrm{n}=$ & & & 1360 & 1765 & & 687 & 326 & 302 & 346 & 270 & 219 & 249 & 431 & 295 & & & \\
\hline
\end{tabular}

\# The prescribed volume is given in total numbers of Defined Daily Doses (DDDs) prescribed and the mean numbers of DDDs per prescription (DDD/P).

$\Delta$ The $95 \%$ confidence interval for the difference between the proportions does not include zero (!), or does include zero (-).

* Some preparations and drug groups (ATC) do not have a DDD. Among these are: plasma substitutes and perfusion solutions (B05), other haematological agents (B06), dermatologicals for topical use (D), otologicals (S02), ophthalmo-/otological preparations (S03), other therapeutic products (V03), and diagnostic agents (V04).

** The ATC anatomical main classes (numbers of prescriptions): Blood and bloodforming organs (16), Dermatologicals (70), Genitourinary system and sex hormones (46), Systemic hormonal preparations excl. sex hormones (42), Antineoplastic and immunomodulating agents (1), Antiparasitic products (4), Various (4).

Table 3. The 10 most frequently prescribed drugs for patients during home visits in general practice by ATC system therapeutic groups and the three most commonly recorded diagnostic indications (\%) for prescribing within each therapeutic group.

\begin{tabular}{|c|c|c|c|c|c|c|c|c|c|}
\hline \multicolumn{3}{|c|}{ Drugs } & \multicolumn{6}{|c|}{ The three most commonly recorded diagnoses for prescribing $(\%)$} & \multirow{2}{*}{$\begin{array}{r}\text { Diagnoses } \\
1+2+3(\%) \\
\text { of all }\end{array}$} \\
\hline $\begin{array}{r}\text { ATC- } \\
\text { No. code }\end{array}$ & Therapeutic group & $\begin{array}{c}\% \text { of all } \\
\text { prescriptions }\end{array}$ & 1. diagnosis & $\%$ & 2. diagnosis & $\%$ & 3. diagnosis & $\%$ & \\
\hline 1. J01 & Antibiotics & 36.7 & Acute bronchitis & 15 & Otitis & 14 & Tonsillitis & 13 & 42 \\
\hline 2. N02 & Analgesics & 10.7 & Low back pain & 17 & Pain, unspecified & 7 & Fever & 6 & 30 \\
\hline 3. N05 & Psycholeptics & 8.0 & Insomnia & 28 & Anxiety & 25 & Depression & 8 & 61 \\
\hline 4. R01 & Rhinologicals & 6.3 & Otitis & 38 & Sinusitis & 22 & UpperRespTractInfect & 21 & 81 \\
\hline 5. S01 & Opthalmologicals & 4.5 & Infect. conjunctivitis & 45 & Foreign body in eye & 25 & Other conjunctivitis & 5 & 75 \\
\hline 6. R05 & Cough/cold prep. & 4.4 & UpperRespTractInfect & 57 & Acute bronchitis & 18 & Pneumonia & 7 & 82 \\
\hline 7. R03 & Anti-asthmatics & 3.7 & Asthma & 56 & Acute bronchitis & 13 & UpperRespTractInfect & 13 & 82 \\
\hline 8. M01 & NSAIDs & 3.7 & MusclesTendonsJoints* & 39 & Arthritis/arthrosis & 22 & Low back pain & 11 & 72 \\
\hline 9. M03 & Muscle relaxants & 2.3 & Low back pain & 39 & MusclesTendonsJoints* & 32 & Neck pain & 7 & 78 \\
\hline 10. $\mathrm{C} 03$ & Diuretics & 1.9 & Heart failure & 62 & Peripheral oedemas & 15 & Hypertension & 8 & 85 \\
\hline
\end{tabular}

\begin{tabular}{lll}
\hline Sum $(1-10) \%$ & 82.2 \\
Others \% & 17.8
\end{tabular}$\quad *$ Muscles, joints and tendons: unspecified symptoms and complaints

$\mathrm{N}=(100 \%)$

The distribution of different diagnostic groups in patients seen in Norwegian general practice has previously been reported to be quite stable over time. ${ }^{3,17}$ Drug prescribing practice may, however, change a lot over years. However, we think that this is mainly for single compounds, not affecting so much the data reported here: the distribution between the various ATC anatomical main groups, and the ATC therapeutic main groups. We therefore believe that our data regarding drugs still are relevant for general practice today even if they were recorded in 1988 and 1989.

\section{Results}

This study has confirmed earlier findings that children and elderly people are most prone to receive home visits by their GP. ${ }^{6,11,18}$ A rate of 130 home visits per 1000 inhabitants per year is close to what was reported in a previous Norwegian study from $1982,{ }^{18}$ but considerably lower than a UK rate of 299 home visits per 1000 inhabitants per year. ${ }^{6}$ The difference between Norway and UK is most pronounced for the very old. In our sample the rate was 362 visits per 1000 inhabi- 
Table 4. Multiple logistic regression analysis of doing home visit $(\mathrm{n}=4,266) v s$. other types of contact $(\mathrm{n}=68,244)$.

\begin{tabular}{lrc}
\hline & Odds ratio & $95 \%$ CI \\
\hline $\begin{array}{l}\text { Demography, time and } \\
\text { type of encounter: }\end{array}$ & & \\
Male patient & 1.08 & $1.01-1.16$ \\
Age 0-9 years & 2.43 & $2.21-2.66$ \\
Age 10-19 years & 1.36 & $1.21-1.53$ \\
Age 70-79 years & 1.90 & $1.72-2.11$ \\
Age $\geq 80$ years & 3.32 & $2.95-3.73$ \\
Weekend & 14.06 & $12.82-15.43$ \\
First contact & 3.54 & $3.29-3.81$ \\
Doctors' characteristics: & & \\
Male doctor & 1.42 & $1.29-1.56$ \\
Young doctor & 1.17 & $1.08-1.27$ \\
GP specialist & 1.18 & $1.09-1.28$ \\
Rural location & 1.71 & $1.54-1.90$ \\
Fixed salary & 1.18 & $1.09-1.27$ \\
\hline
\end{tabular}

tants 80 years and older, while Aylin et al. reported a rate of 3,009 visits per 1000 inhabitants 85 years and older. ${ }^{6}$ This difference may partly be due to the fact that in the UK, mandatory and annual home visits for those aged 75 or more have been introduced by law. ${ }^{19}$

When home visiting rates are given as the proportion of all face-to-face contacts, however, the numbers are very similar in Norway and UK $(9.2 \% v s .10 .1 \%){ }^{6}$ Thus, it seems that differences in contact rates between Norway and UK affect surgery consultations and home visits to an equal degree.

The greying of the population during the last decades resulting in larger numbers of elderly home dwelling inhabitants, may be one explanation for the increase in home visiting rates as compared with those reported from the 1970 's. ${ }^{3,4}$ However, our results may indicate that Norwegian GPs perform too few home visits to the housebound elderly. On the other hand, many home visits for children could probably have been replaced by telephone consultations or by consultations in the surgery. Children account for a large proportion of night visits, ${ }^{12}$ and therefore put a heavy strain on GPs on call.

The different diagnostic profiles between the age groups probably reflect differences in illness prevalence: infections in the respiratory tract dominating among the young, whereas coronary heart disease (CHD) and heart failure (HF) become more predominant among the elderly. This diagnostic pattern has also been found in similar surveys in other countries. ${ }^{6,11,20}$

That HF was the most commonly recorded diagnosis for seeing the oldest in their homes, underline the importance of this health problem among the oldest. The prevalence of HF in the elderly is about $10 \%,{ }^{21}$ and $\mathrm{HF}$ is the most common diagnosis for hospital readmissions in elderly patients. ${ }^{22}$ This corresponds with our finding that about every fifth patient seen for HF was admitted to hospital.

The diagnoses recorded suggest that most home visits are prompted by acute and new illnesses (infections, trauma), or acute worsening of known disease (CHD, HF). Also considering that more than one quarter of the visits were performed during weekends, it is probable that home visits in Norwegian general practice in most cases are house calls performed on duty out of hours. We did not differ between "acute" and "scheduled" home visits, but in a previous Norwegian study it was found that $72 \%$ of the home visits were not scheduled. ${ }^{18}$ A large proportion of these patients could probably have been more appropriately assessed by telephone consultation or at walk-in emergency care centres. ${ }^{14}$

During the last years, several studies have indicated that substantial health benefits can be achieved by organizing preventive home visits for the frail olds, and for the chronically ill. ${ }^{23,24}$ In Denmark, Hendriksen and coworkers have performed a three year controlled study showing that intervening with preventive home visits every third month for the olds living in the community, may have substantial impact on hard endpoints like mortality and morbidity, and at the same time cost-saving in terms of less hospitalization, less use of nursing homes, and less use of house calls on duty out of hours. ${ }^{23}$ Our results indicate that such physician-initiated visits rarely occur in Norwegian general practice. The National Health Administration should encourage a shift in the indications and the content of home visits in general practice to more planned home visits by their own GP to the chronically ill, the disabled, and the frail olds.

Large variations in home visiting rates between individual doctors and practices have previously been reported. ${ }^{6}$ We found that the doctor's characteristics most strongly associated with doing house calls were rural location and male gender. Similar findings have also been reported by others. ${ }^{18,20,25}$ It may be that a higher doctor/patient density in rural areas allows for more frequent home visits. Concerns about personal safety have been stated as a reason for not doing home visits, ${ }^{25}$ and it could be that this is mostly a concern for female GPs. Another explanation for the gender difference is the general workload. Male doctors work significantly more hours per week than females, but female doctors do much more housework than their male counterparts do. ${ }^{26}$

\section{CONCLUSION}

Home visits are still an important part of general practice, and young children and the elderly are the main beneficiaries. Respiratory infections in children 
and heart diseases in the old are the main reasons for doing home visits. Our findings indicate that the home visiting policy should be more selective. While most children could be adequately taken care of by telephone consultations or consultations in the surgery, home visits should be encouraged for the housebound and the chronically ill.

\section{ACKNOWLEDGEMENTS}

We thank Kirsten Rokstad for her important contributions in running the main survey of the Møre \& Romsdal Prescription Study during 1988 and 1989, and for her initial handling of the data. We also thank all the GPs in Møre \& Romsdal for their help in providing the data.

\section{REFERENCES}

1. Larsen $\varnothing(\mathrm{ed})$. The shaping of a profession. Physicians in Norway, past and present. Canton: Science History Publications, 1996.

2. Bentsen BG. Illness and general practice. Oslo: Universitetsforlaget, 1970.

3. Rutle O. Focus on the patient. An analysis of contacts with the general practitioner [In Norwegian]. Report No 1/1983. Oslo: Unit for Health Services Research, 1983.

4. Øgar B. Patients in Norwegian general practice [In Norwegian]. Oslo: Universitetsforlaget, 1977.

5. Bruusgaard D. Contacts and referrals in Norwegian general practice [In Norwegian, English summary]. Tidsskr Nor Lageforen 1994; 114: 174-6.

6. Aylin P, Majeed FA, Cook DG. Home visiting by general practitioners in England and Wales. BMJ 1996; 313: 207-10.

7. Campion EW. Can house calls survive? N Engl J Med 1997; 337: 1840-1.

8. Fugelli P. The future for the home visit [In Norwegian]. Tidsskr Nor Laegeforen 1978; 98: 1189.

9. McWhinney IR. Fourth annual Nicholas J. Pisacano lecture. The doctor, the patient, and the home: returning to our roots. J Am Board Fam Pract 1997; 10: 430-5.

10. Taler G. House calls for the 21st century. J Am Geriatr Soc 1998; 46: 246-8.

11. de Melker RA, van der Velden J, Kuyvenhoven MM. House calls for respiratory infections; family medicine pure and simple? Fam Pract 1995; 12: 294-8.

12. Majeed FA, Cook DG, Hilton S, Poloniecki, Hagen A. Annual night visiting rates in 129 general practices in one family health services authority: association with patient and general practice characteristics. $\mathrm{Br} J \mathrm{Gen}$ Pract 1995; 45: 531-5.

13. Whynes DK, Baines DL. Explaining variations in the frequency of night visits in general practice. Fam Pract 1996; 13: 174-8.

14. Christensen MB, Olesen F. Out of hours service in Denmark: evaluation five years after reform. BMJ 1998; 316: $1502-5$.

15. Rokstad K, Straand J, Fugelli P. General practitioners' drug prescribing practice and diagnoses for prescribing: The Møre \& Romsdal Prescription Study. J Clin Epidemiol 1997; 50: 485-94.

16. WHO and NCM. Guidelines for ATC-classification. Oslo and Uppsala: WHO Collaborating Centre for Drug Statistics Methodology (Oslo) and Nordic Council of Medicines (Uppsala), 1990.

17. Rokstad K, Straand J, Sandvik H. Patient encounters in general practice. An epidemiological survey in Møre and Romsdal [In Norwegian, English summary]. Tidsskr Nor Laegeforen 1997; 117: 659-64.

18. Kristiansen IS, Holtedahl K. Effect of the remuneration system on the general practitioner's choice between surgery consultations and home visits. J Epidemiol Community Health 1993; 47: 481-4.

19. Freer CB. Screening the elderly. BMJ 1990; 300: 1447-8.

20. Meyer GS, Gibbons RV. House calls to the elderly - a vanishing practice among physicians. $N$ Engl J Med 1997; 337: 1815-20.

21. Kannel WP, Belanger AJ. Epidemiology of heart failure. Am Heart J 1991; 121: 174-9.

22. Gooding J, Jette AM. Hospital readmissions among the elderly. J Am Geriatr Soc 1985; 33: 595-601.

23. Hendriksen C, Lund E, Strømgård E. Consequences of assessment and intervention among elderly: a 3 year randomised controlled trial. BMJ 1984; 289: 1522-4.

24. van Rossum E, Fredriks CMA, Philipsen H, Portengen K, Wiskerke J, Knipschild P. Effects of preventive home visits to elderly people. $B M J 1993 ; \mathbf{3 0 7}$ : 27-32.

25. Adelman AM, Fredman L, Knight AL. House call practices: a comparison by specialty. J Fam Pract 1994; 39: 39-44.

26. Hofoss D, Gjerberg E. Norwegian doctors' working hours [In Norwegian, English summary]. Tidsskr Nor Logeforen 1994; 114: 3059-63. 